\title{
Self-Locking Hydrostatic Differential for Automated Agriculture Spray Vehicle
}

\author{
Rohit S. Belsare*, Avinash Badadhe

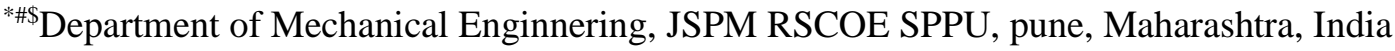

(Received 13 January 2021; Accepted 15 March 2021)

https://doi.org/10.36224/ijes.140103

\begin{abstract}
The differential is an important part of the automobile transaxle. The purpose of the differential is to distribute power to the two rear wheels and provide differential speed to the vehicle wheels when the vehicle takes a turn. Conventional differentials although provide the differential speeds but fails to prevent slip of the differential. In vehicles for application in agriculture it is essential to have differential locking due to slippery conditions hence a differential locking system is needed. Limited slip differentials are available but they are very costly and also they do not offer complete differential locking. Present solutions available in market are either too primitive where in the driver has to get down from the vehicle and then lock the differential or they are very sophisticated in the form of E-locker from EATON which is very costly to implement in commercial vehicles. The project work aims at design development of self-locking differential locking system for an automated agriculture vehicle where in the differential drive and the locking arrangement will be both hydraulically operated. The components will be designed used Unigraphix software and the analysis of the components will be done using Ansys work bench. Further the developed hydrostatic differential model will be tested to determine the performance characteristics of the drive.
\end{abstract}

Keywords: Hydraulic Differential, Self-Locking Differential, Agriculture vehicle differential, Hydrostatic Differential

\section{Introduction}

The Transmission System's Parts: Transmission system is drive system for your vehicle. It consists of engine, Clutch, Gear box, drive Shaft and Differential system to drive the wheels. The purpose of the transmission is to drive the wheels of the vehicle. Also it helps us to connect \& disconnect the Gears from Drive system with help of the clutch.

From the gearbox, a propeller shaft goes to the rear end of the vehicle, to the rear axle (in case of a rear wheel drive). The axle on which the drive shaft or power drive is mounted is called the live axle. A live axle is called as live because the drive system is mounted on it and it transmits the power to the wheel, while on the other hand the dead axle doesn't transmits any power to the wheels. The live axle has a differential gear system which divides the Torque/power from the propeller shaft equally between the two half-axles to the wheels.

The clutch is operated on the principle of spring loaded mechanism which is operated with the help of pedal.

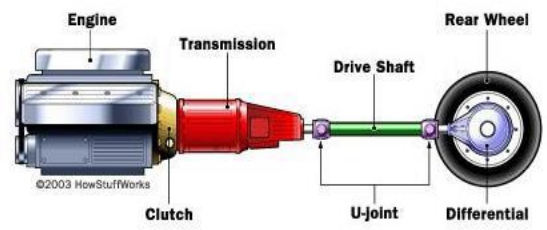

Figure 1: Automobile Powertrain System 


\section{Literature review}

Amit Suhane , R. S. Ranaa, N.D. Rajesh Purohit [1]. The four wheel drive is useful in handling of the vehicle in critical conditions such as slippery road, muddy, snow ice road off road conditions. In present scenario vehicle are using four wheel drive and two wheel drive which can be changes easily by manually or automatically using gearing mechanisms. The sensors allow vehicles to automatically change the two wheel drive to four wheel drive through sensing of the road conditions. The research shown that there are transmission and drive losses so there are many researches going on four wheel drives to improve maneuverability and performance of four wheel drive system. Now it is more important to have better performing differential system which is self-operated.

A.V. Keller, A.A. Shelepov, D.I. Istomin [2]. The research dwells upon the nonlinear dynamic model of the vehicle four wheel drive system with a screw-ball differential. The car model is imported in the software package LMS . in this they implemented a limited slip differential system as it almost used in every vehicle as it was very promising and efficient, enabling simultaneously to improve safety .

Waghmare A.S ,Shinde S.V, Kavale A.S , Prof. Tathe P.G [3]. A conventional differential is used to transmit the torque equally to both the wheels . while turning automobile differential transmits torque to the wheel which has less traction and it will rotates at twice the normal speed. Differential locking system here is introduce to engage and disengage as per requirement of the road conditions or as per will of the operator which is automated or manually . the planetary gear spike shaft is used to lock the differential.. if there is change in torque in wheels the differential lock is engaged.. when the vehicle is running on sloppy road due to pots or improper leveling of the road there is an change in speeds of the two wheels which will cause problems in running vehicle smoothly.

\subsection{Problem definition/formulation}

The problem of the differential is if one of the wheel held stationary the other wheel starts to rotate at twice of its normal speed. This can be problematic when one wheel got stuck in mud-pot or snow the traction in that wheel can be zero.so the other wheel stops rotating and all the traction is provided to other wheel by differential system. but if the wheel which is stuck in mud pot has lost its contact with the ground it will not take the vehicle out from the mud pot.The other wheel is stationary so it is not possible for vehicle to come out from the pot. To overcome this the differential locking is used. It will lock the differential and transmit the torque to both the wheels so that the vehicle can be taken out.

\section{Design \& Analysis}

\subsection{Design of differential locking system}

\subsubsection{Motor selection}

Considering that the maximum rear wheel diameter for the vehicle $=10 \times 25.4=254 \mathrm{~mm}$

Traction Coefficients for normal Car Tires

The tractive force between a car wheel and the surface can be expressed as

$\mathrm{F}=\mu \mathrm{t} \mathrm{W}=\mu \mathrm{tm} \mathrm{ag}$

$\mathrm{F}=0.9 * 25 * 9.81=220.7 \mathrm{~N}$

Torque $=\mathrm{F}$ x Radius of wheel $=220.7 * 0.127=28.089 \mathrm{~N}-\mathrm{m}$

As we are to provide 44 teeth chain wheel on the differential the reduction ratio between motor and the wheel shaft $=44 / 9=4.88$

Thus minimum torque of motor required $=28.089 / 4.88=5.75 \mathrm{~N}-\mathrm{m}$ 
Thus selecting motor as below:

Considering $80 \%$ effciciency of transmission

Torque from motor $=8 \mathrm{~N}-\mathrm{m}$

3.2. Design of wheel shaft
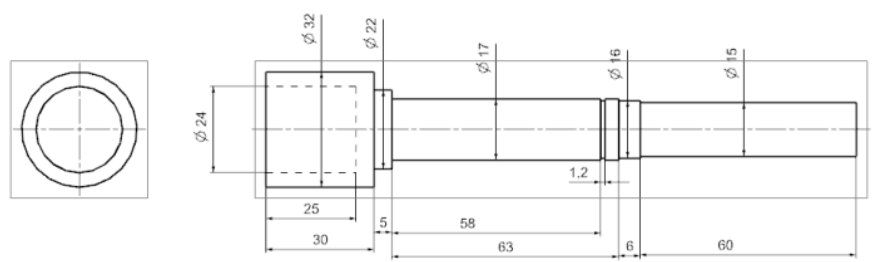

Figure 2: wheel shaft

Since the loads on most shafts in connected machinery are not constant, it is necessary to make proper allowance for the harmful effects of load fluctuations

According to ASME code permissible values of shear stress may be calculated form various relation.

fs $\max =0.18=0.18 \times 800=144 \mathrm{~N} / \mathrm{mm}^{2}$

Shaft is provided with key way; this will reduce its strength. Hence reducing above value of allowable stress by $25 \%$

fs $\max =108 \mathrm{~N} / \mathrm{mm} 2$

This is the allowable valve of shear stress that can be induced in the shaft material for safe operation.

$\mathrm{T}=8 * 4.88 / 2=19.05 \mathrm{~N} . \mathrm{m}$

\subsubsection{Check for torsional shear failure of shaft}

Assuming minimum section diameter on input shaft $=16 \mathrm{~mm}$

$\mathrm{d}=16 \mathrm{~mm}$

$\mathrm{T}_{\mathrm{d}}=\pi / 16 * \mathrm{fs}_{\mathrm{act}} * \mathrm{~d}_{3}$

$\mathrm{fs}_{\text {act }}=\frac{16 * \mathrm{~T}_{\mathrm{d}}}{\pi * \mathrm{~d} 3}=\frac{16 * 19.05-10^{3}}{\pi *(15)^{3}}$

$\mathrm{fs}_{\text {act }}=28.74319259 \mathrm{~N} / \mathrm{mm}^{2}$

As fs act $<$ fs all

LH wheel shaft is safe under torsional load

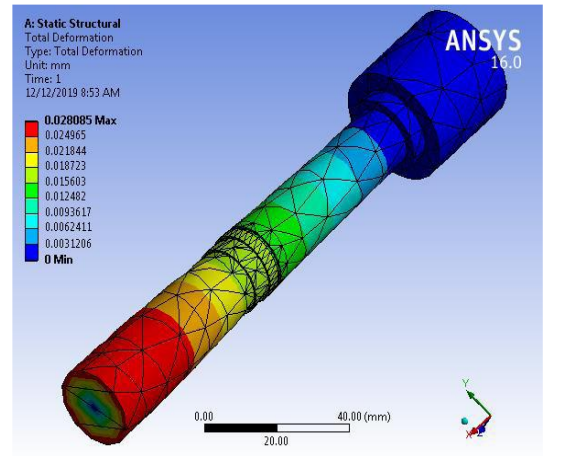

Figure 4: Total Deformation of shaft

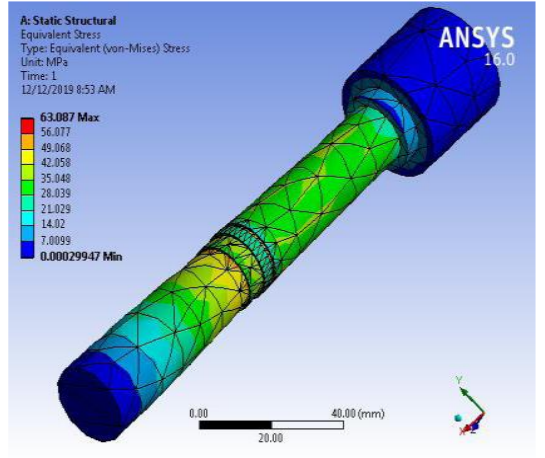

Figure 5: Structure analysis 
Maximum Von-misses stresses in the part are 63.08 MPa which is far below the allowable value $108 \mathrm{MPa}$ hence the part is safe under given loading conditions. The maximum deformation in the part is $0.02 \mathrm{~mm}$, which is very negligible hence the part is safe.

\subsection{Design of spike shaft}

\subsubsection{Material selection}

Table 1: Material selection: - Ref:- PSG (1.10 \& 1.12) + (1.17)

\begin{tabular}{|c|c|c|}
\hline Designation & Ultimate tensile strength $(\mathrm{N} / \mathrm{mm} 2)$ & Yeild strength $(\mathrm{N} / \mathrm{mm} 2)$ \\
\hline EN24 & 800 & 680 \\
\hline
\end{tabular}

\subsubsection{ASME code for design of shaft}

Since the loads on most shafts in connected machinery are not constant, it is necessary to make proper allowance for the harmful effects of load fluctuations relation.

According to ASME code permissible values of shear stress may be calculated form various

fs $\max =0.18$ fult $=0.18 * 800=144 \mathrm{~N} / \mathrm{mm} 2$ or fs $\max =0.3 \mathrm{fyt}=0.3 * 680=204 \mathrm{Mpa}$

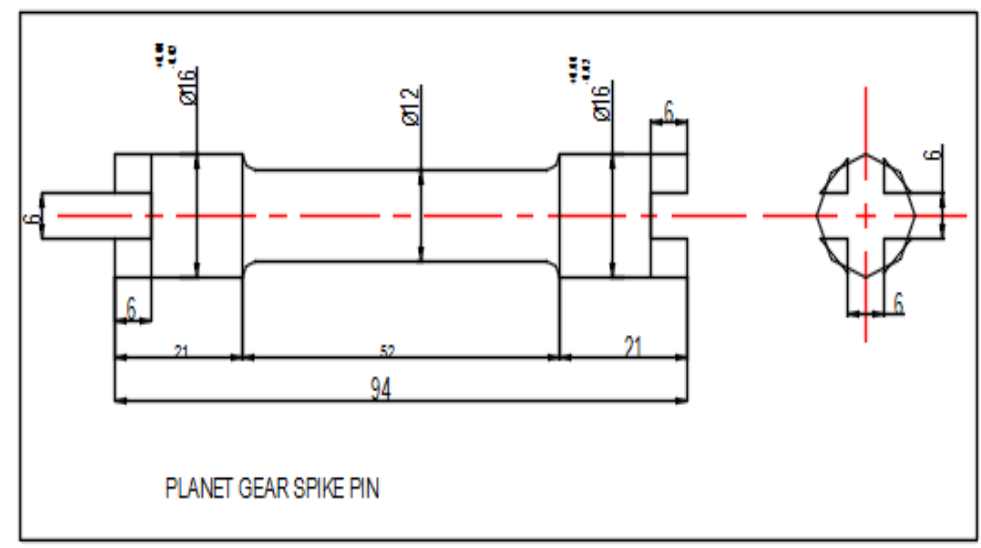

Figure 6: Design of Spike shaft

considering minimum of the above values ;

fs $\max =144 \mathrm{~N} / \mathrm{mm} 2$

Shaft is provided with key way; this will reduce its strength. Hence reducing above value of allowable stress by $25 \%$

fs $\max =108 \mathrm{~N} / \mathrm{mm} 2$

This is the allowable valve of shear stress that can be induced in the shaft material for safe operation.

\subsubsection{To calculate input torque}

Power $=\frac{2 \pi \mathrm{NT}}{60}$

$\mathrm{T}=\frac{60 * \mathrm{P}}{2 \pi \mathrm{N}}=\frac{60 * 50}{2 \pi \mathrm{N}}$

Assuming operation speed $=800 \mathrm{rpm}$. 
$=\frac{60 * 50}{2 \pi * 800}$

$\mathrm{T}=0.5968 \mathrm{~N} \cdot \mathrm{m}$

Assuming 100\% overload.

$\mathrm{T}$ design $=39.1 / 4=9.8 \mathrm{~N}-\mathrm{m}$

\subsubsection{Check for torsional shear failure of shaft}

Assuming minimum section diameter on input shaft $=16 \mathrm{~mm}$

$\mathrm{d}=16 \mathrm{~mm}$

$\mathrm{T}_{\mathrm{d}}=\pi / 16 * \mathrm{fs}_{\text {act }} * \mathrm{~d}_{3}$

$\mathrm{fs}_{\mathrm{act}}=\frac{16 * \mathrm{~T}_{\mathrm{d}}}{\pi * \mathrm{~d}^{3}}=\frac{16 * 9.81 * 10^{3}}{\pi * 16^{3}}$

$\mathrm{fs}_{\text {act }}=14.80161256 \mathrm{~N} / \mathrm{mm}^{2}$

As fs act $<$ fs all, Spike shaft is safe under torsional load

\subsubsection{Von-mises Stresses}

The maximum Von-misses stresses in the part are 54.276 MPa which is far below the allowable value 108 MPa hence the part is safe under given loading conditions. The maximum deformation in the part is 0.029 $\mathrm{mm}$, which is very negligible hence the part is safe.

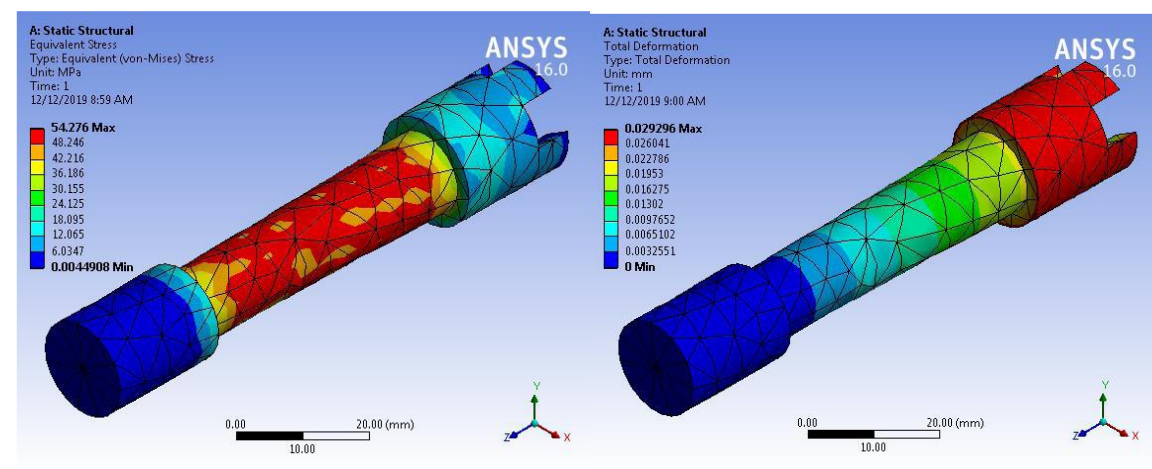

Figure 7: Static analysis

Figure 8: Total Deformation

\subsection{Design of dog ring}

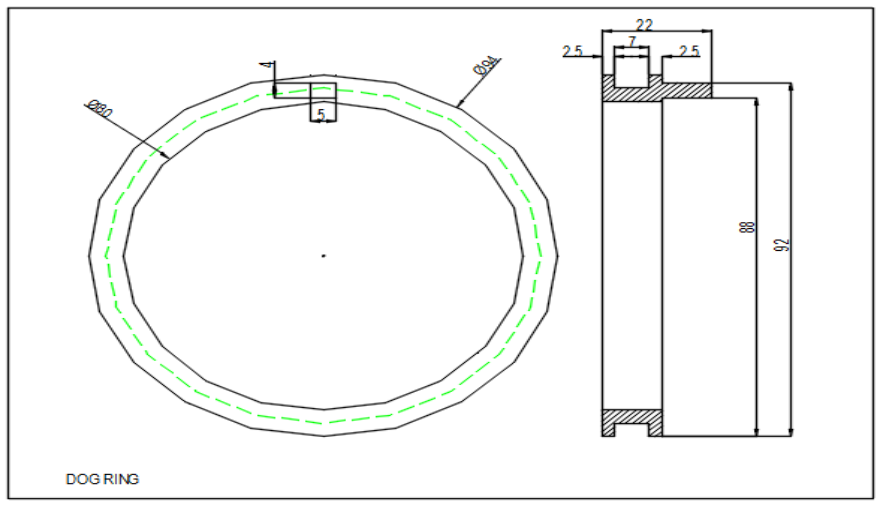

Figure 9: Dimensions of Dog ring 
Table 2: Material selection: - Ref:- PSG (1.10 \& 1.12) + (1.17)

\begin{tabular}{|c|c|c|}
\hline Designation & Ultimate tensile strength $(\mathrm{N} / \mathrm{mm} 2)$ & Yeild strength $(\mathrm{N} / \mathrm{mm} 2)$ \\
\hline EN24 & 800 & 680 \\
\hline
\end{tabular}

'Dog is located on pcd $72 \mathrm{~mm}$. These pins engage in the cage of the spike shaft and act as transmission elements.They can be designed similar to the bush pins in the bush pin type flexible flange coupling.

'Three pins' transmit the entire torque;

These pins are located at PCD $(\mathrm{Dp})=72 \mathrm{~mm}$

Tangential force on each bolt

$\mathrm{F}_{\mathrm{b}}=\frac{\mathrm{T}}{\mathrm{D}_{\mathrm{p}} * \mathrm{n} / 2}$

$\mathrm{T}=\frac{\mathrm{D}_{\mathrm{p}} * \mathrm{n} * \mathrm{~F}_{\mathrm{b}}}{2}$

Shear stress $=\frac{\text { Shear force }}{\text { Shear area }}$

$\mathrm{fs}_{\mathrm{act}}=\frac{\mathrm{F}_{\mathrm{b}}}{\pi / 4 * \mathrm{~d}^{2}}$

$\mathrm{F}_{\mathrm{b}}=\mathrm{fs}_{\mathrm{act}} * \pi / 4 * \mathrm{~d}^{2}$

$\mathrm{T}=\frac{\mathrm{D}_{\mathrm{p}} * \mathrm{n} * \mathrm{fs}_{\mathrm{act}} * \pi / 4 * \mathrm{~d}^{2}}{2}$

Assuming Pin diameter $=5 \mathrm{~mm}$

$9.81 * 10^{3}=\frac{72 * 1 * \mathrm{fs}_{\mathrm{act}} * \pi * 5^{2}}{8}$

$\mathrm{fs}_{\text {act }}=29.45 \mathrm{~N} / \mathrm{mm}^{2}$

As fs act $<$ fs all, Pins are safe under shear load.

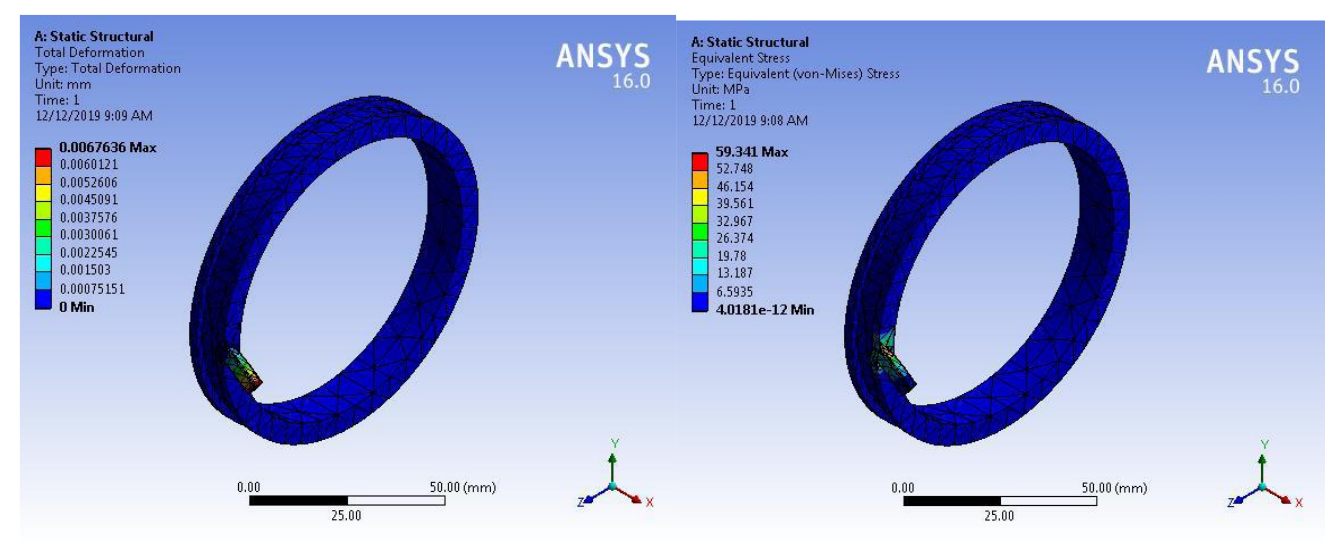

Figure 10: Total Deformation

Figure 11: Static analysis

Maximum Von-misses stresses in the part are 54.9 MPa which is far below the allowable value 108 MPa hence the part is safe under given loading conditions. The maximum deformation in the part is $0.0067 \mathrm{~mm}$, which is very negligible hence the part is safe.

Design of hydraulic Cylinder for engagement of Dog ring: 
Design and Analysis of Hydraulic Cylinder

Hoope's stress due to oil pressure:-

Maximum pressure induced in system due to oil $=30 \mathrm{bar}$.

$\mathrm{fc}_{\mathrm{h}}=\mathrm{P} * \mathrm{~d}$

$\mathrm{fs}_{\mathrm{act}}=\frac{3 * 25}{2 * 2.5}$

As fc $\mathbf{h}<\mathrm{fc}$ all ; Cylinder is safe

Longitudinal stress due to oil pressure:-

Maximum pressure induced in system due to oil $=30 \mathrm{bar}$

$\mathrm{fc}_{1}=\frac{\mathrm{P} * \mathrm{~d}}{4 \mathrm{t}}$

$\mathrm{fc}_{\text {lact }}=\frac{3 * 25}{4 * 2.5}$

$\mathrm{fc}_{\mathrm{lact}}=30 \mathrm{~N} / \mathrm{mm}^{2}$ As fc $1<\mathrm{fc}$ all $;$ cylinder is safe.

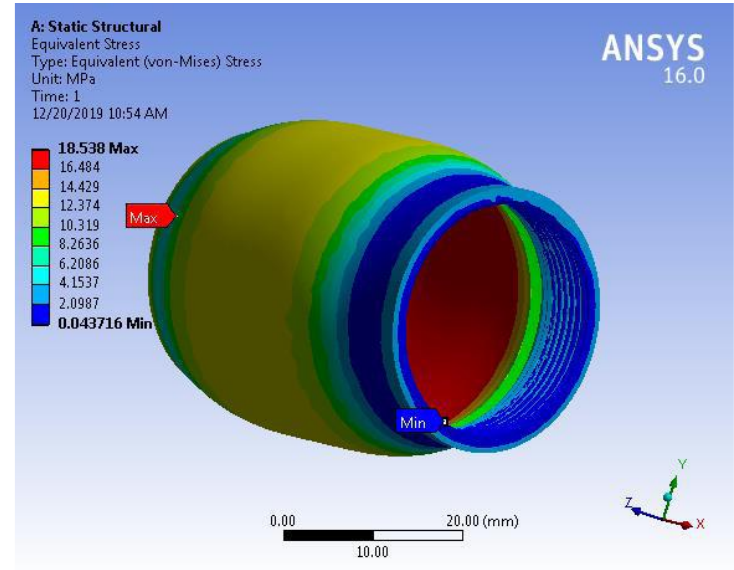

Figure 16: Static Analysis

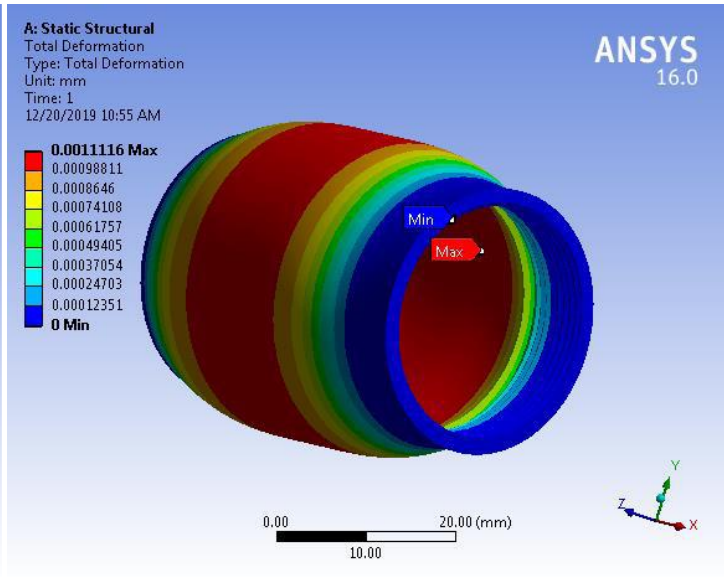

Figure 17: Total Deformation

As the maximum stress induced in the part theoretical (15 MPa) and the analytical maximum von-misses stress $(18 \mathrm{MPa})$ are well below permissible limit, the cylinder is safe. The part shows negligible deformation under the given pressure it is safe.

\section{Results and discussion}

Design of differential locking mechanism, for semi-automatic version. Making the total Drive on single Hydrostatic power without using the engine, Gearbox, clutch, system to reduce its weight and size and operating Differential and the drive system on single hydraulic motor.

Also next we are going to Testing \& Inspection of the working of this differential system with installation on the agriculture vehicle.

\section{Conclusion}

1. The differential system can be installed easily on every agriculture vehicle without disturbing its other parts.

2. Removal of power system reduced the weight of vehicle \& increased its mobility. 
3. The cost \& Weight of the Vehicle is reduced \& also the vehicle made is very constrained

\section{References}

[1] Amit Suhanea, R. S. Ranaa and Rajesh Purohitb , Prospects of Torsen Differential in Four Wheel Drive Automobile Transmission System,Materials Today: Proceedings 5 (2018) 4036-4045 () 2017 Elsevier Ltd.

[2] A.V. Keller, A.A. Shelepov, D.I. Istomin, Estimation of Screw-Ball Differential on Vehicle Dynamics, International Conference on Industrial Engineering, ICIE 2016

[3] Waghmare A. Shinde S.V Kavale A.S Prof. Tathe P.G, Differential Locking System, International Journal for Scientific Research \& Development| Vol. 4, Issue 12, 2017 | ISSN (online): 2321-0613

[4] S. Todkar, R. S. Kapare, Design Development and Testing of Automatic differential locking system, International Journal of Advanced Engineering Technology

[5] Vinod P.Sakhare, Ajinkya D.Wadatkar, Gaurav B. Lohakare, Nikhil G.Narad4, Advances in Motion Control of Rear Wheels of Automobile Differential Using wheel Locking System, April 2016, Volume 3, Issue 4 JETIR (ISSN-2349-5162) 